\title{
EFECTO DE EXTRACTOS CETÓNICOS DE HIGUERILLA (Ricinus communis LINNEO.) SOBRE EL NEMATODO BARRENADOR [Radopholus similis (COBB.) THORNE] EN CONDICIONES IN VITRO
}

\author{
FRANCISCO DE JESÚS ARBOLEDA ${ }^{1}$ \\ ÓSCAR ADRIÁN GUZMAN ${ }^{2}$ \\ LUÍS FERNANDO MEJIIA ${ }^{3}$
}

Recibido el 11 de abril de 2012 y aprobado el 20 de agosto de 2012

\begin{abstract}
RESUMEN
Los nematicidas utilizados para el control de nematodos fitoparásitos son costosos y contaminan los ecosistemas terrestres y acuáticos, debido a ello se buscó otra alternativa para su manejo, como fue evaluar el efecto de extractos cetónicos (metodología de Soxhlet) de raíces, tallos, hojas y frutos de higuerilla (Ricinus communis) en tres concentraciones de 25, 50 y $100 \%$, comparándolos con los testigos agua y químico (Carbofuran) sobre $R$. similis en condiciones in vitro. Se aplicaron $2 \mathrm{~mL}$ de cada extracto sobre 50 hembras de $R$. similis depositadas en cajas de Petri. Después de $48 \mathrm{~h}$, se evaluó el efecto nematicida y nemostático de los extractos bajo un diseño experimental completamente al azar. En los tres tiempos de lectura, los tratamientos de los extractos cetónicos de frutos, raíces y hojas de higuerilla en la concentración de $100 \%$, tuvieron un efecto nematicida entre 73 y $89 \%$, sin diferencias estadísticas significativas al testigo químico que tuvo valores entre 82 y $98 \%$;estos tratamientos presentaron diferencias estadísticas significativas con el testigo agua que presentó valores menoresentre 0,7 y $12 \%$. La prueba de Bradford permitió conocer la presencia de proteínas en los extractos cetónicos de los tejidos de higuerilla, confirmando que el extracto cetónico de frutos tuvo una cantidad alta de Albúmina,probablemente ricina, que influyó en la mortalidad mayor de $R$. similis.
\end{abstract}

\section{PALABRAS CLAVE:}

Nematodo, concentración, proteína.

\section{EEFFECTS OF CASTOR-OIL PLANT (Ricinuscommunis LINNEO) KETONE EXTRACTS ON THE BURROWING NEMATODE [Radopholussimilis(COBB) THORNE] UNDER IN VITRO CONDITIONS}




\begin{abstract}
Nematicides used for phytoparasite nematodes control are expensive and pollute land and water ecosystems. Because of this, an alternative for their handling was looked for, as it was the evaluation of the effect of ketone extracts (Soxhlet's method) in higuerilla (Ricinus communis) roots, stems, leaves and fruits in three concentrations of 25, 50 and $100 \%$, comparing them to water and chemical (Carbofuran) controls on $R$. similis in vitro conditions. Two $\mathrm{mL}$ of each extract were applied on 50 female $R$. similis placed on Petri dishes. After $48 \mathrm{~h}$, the extracts nematicide and nemostatic effect under a completely randomized experimental design was evaluated. In the three reading times, the higuerilla fruits, roots and leaves ketone extracts in the $100 \%$, concentration had a nematicidal effect between 73 and $89 \%$ without significant statistic differences with the chemical control which had values between 82 and $98 \%$. These treatments presented differences statistically significant with the water control which showed lower values between 0.7 and $12 \%$. Bradford's test allowed to detect the presence of proteins in higuerilla ketone tissues extracts confirming that the ketone fruit extract had a high amount of albumin, possibly caster oil, which influenced the increased mortality of $R$. similis.
\end{abstract}

\title{
KEY WORDS:
}

Nematodes, concentration, protein.

\section{INTRODUCCIÓN}

Del cultivo de higuerilla o castor (Ricinus communis L.) hay sembradas 1.280 .197 ha con un rendimiento promedio de $928 \mathrm{kgha}^{-1} \mathrm{y}$ una producción de $1.191 .443 t$. El principal productor mundial es la India con $800.000 t$, lo que equivale a cerca de $70 \%$ de la producción mundial, seguido de la China y Brasil con 268.000 y $176.000 t$, respectivamente (FAOSTAT, 2006). Desde la antigüedad hasta hoy, la semilla de higuerilla ha sido utilizada para extraer aceites que se usan como combustible en lámparas y con fines medicinales como purgante (Scarpa \& Guerci, 1982; Mazzani, 2007). Debido a que las semillas son venenosas por la presencia de metabolitos secundarios como albúminas, ricina, y alcaloides, ricinina, que son utilizados como nematicida e insecticida para el control de plagas en los cultivos (Topping et al. 1982; Moshkin, 1986; Holfelder et al. 1998; Acacio-Bigi et al. 1998; Céspedes et al. 2001; Kouri et al. 2006; Corpoica, 2008). 
La ricina, es una fitotoxina que se encuentra principalmente en las semillas de higuerilla, y es la responsable de la toxicidad a animales como nematodos, insectos, entre otros (Moshkin, 1986). La ricina está entre las proteínas de mayor toxicidad en el mundo conocidas por el hombre, ya que hace parte del grupo de proteínas inactivadoras de ribosomas, RIPs, de tipo 2, que se caracterizan por presentar dos cadenas polipeptídicas: una capaz de inhibir la síntesis de proteínas en los ribosomas y otra con propiedades de lectina, es decir, capaz de unirse a hidratos de carbono (Barbieri et al. 1993; Van Damme et al. 2001).

Los compuestos tóxicos, alcaloides, fenoles, terpenoides, entre otros, y las lectinas tales como la ricina y la ricinusaglutinina, tienen la capacidad para adherirse fuertemente a los anfidios de los nematodos fitoparásitos como Meloidogyne spp. Goeldi, que forma nudos o agallas en el sistema radical, y modificar así su comportamiento quimiotáctico (Marbán et al. 1987; Rich et al. 1989). Rodríguez (2005), encontró que la torta deshidratada de higuerilla cuando es incorporada al suelo en concentraciones de 1,$5 ; 2,0$ y $3,0 \%$ en plántulas de café de 60 días de edad, redujo las poblaciones del nematodo Pratylenchus coffeae Sher \& Allenen 61, 70 y $76 \%$, respectivamente; mientras que Carbofuran redujo la población en 54\%, con relación al testigo. Asimismo, este autor encontró que la higuerilla combate otros fitonematodos como Aphelenchus avenae Bastian, Hoplolaimus indicus Sher, Pratylenchus delattrei Luc, Tylenchorhynchus brassicae Cobb, Helicotylenchus dihystera (Cobb) Sher., y Rotylenchus reniformis Lindford \& Oliveira.

En los cultivos de banano y plátano, después de las lesiones foliares ocasionadas por las Sigatokas negra y amarilla (Mycosphaerella fijiensis Morelet. \& M. musicola Leach \& Mulder, respectivamente), los nematodos fitoparásitos, especialmente Radopholus similis (Cobb.) Thorne, son los principales problemas que afectan su crecimiento y desarrollo, en el mundo, debido al daño ocasionado en raíces y cormos (Araya, 2003; Gowen et al. 2005). R. similis produce lesiones de longitud variable de 5 o más $\mathrm{cm}$., con forma de estrías, éstas inicialmente son de color amarillo claro, luego rosado rojizas y finalmente cafés o negras; en algunos casos produce depresiones en el tejido que modifican la anatomía cilíndrica original de las raíces (Blake, 1961; Thorne, 1961; Fogain \& Gowen, 1997; Valette et al. 1998; Oramas \& Román, 2006). En infestaciones altas, las lesiones rodean completamente las raíces, destruyéndolas totalmente. Dicha coloración se caracteriza por estar infestada con todos los estados de 
desarrollo del nematodo (Sarah et al. 1996; Marín et al. 1998; Araya \& De Waele, 2004; Gowen et al. 2005).

Como consecuencia de lo anterior, en raíces y cormos infectados por $R$. similis se reduce la absorción de agua y nutrientes, resultando en varios síntomas como amarillamiento de hojas, disminución del tamaño y longevidad de las plantas además de menor peso del racimo; así como un incremento del tiempo de siembra a cosecha y entre cosechas (Sarah et al. 1996; Araya, 2003; Gowen et al. 2005). Finalmente, las plantas pierden anclaje por el deterioro del sistema radical, por lo cual tienden a desraizarse o volcarse, esto puede ocurrir en plantas jóvenes y adultas, principalmente entre la época de floración y cosecha debido al peso del racimo, particularmente durante vientos y lluvias fuertes (Loos \& Loos, 1960; Sarah et al. 1996; Montiel et al. 1997; Araya, 2003; Brooks, 2008), lo que reduce el rendimiento (t ha-1) entre 60 y $52 \%$ en la primera y segunda cosecha, respectivamente (Fogain, 2000), aunque la reducción en el rendimiento puede llegar hasta un $80 \%$ (Moens et al. 2004).

El método más utilizado para el control de nematodos fitoparásitos e insectos plaga ha sido el control químico a base de productos sintéticos no fumigantes como organofosforados o carbamatos, los cuales son altamente tóxicos (Sarah et al. 1996). El uso repetitivo de plaguicidas ha inducido la resistencia de plagas y la eliminación de sus enemigos naturales, la alteración del equilibrio dinámico de los ecosistemas terrestres y acuáticos, la muerte de humanos y animales domésticos por intoxicación e incremento en los costos de producción agrícola (Reyes et al., 2000), lo cual ha incrementado las estrategias de manejo integrado de los nematodos fitoparásitos u organismos plaga por medio de agricultura no convencional, específicamente con el uso de metabolitos secundarios producidos por plantas con propiedades nematicidas, insecticidas y fungicidas (Céspedes et al. 2001; González et al. 2006).

Una de las formas de aprovechar estos metabolitos secundarios es mediante la preparación de sus tejidos en extractos vegetales o infusiones, utilizando diferentes solventes como agua, alcohol, éter etílico, aceites, cetonas y benceno (Rodríguez \& Lagunes, 1992; Verduzco et al. 1996). Debido a que la proporción de metabolitos en extractos acuosos es menor, Ramírez et al. (2001), afirman que los extractos obtenidos a partir de solventes orgánicos son mucho más efectivos que los extraídos a base de agua; por tales motivos, el objetivo de esta investigación fue evaluar en condiciones in vitro el efecto de extractos 
cetónicos de raíces, tallos, hojas y frutos de higuerilla ( $R$. communis) sobre el nematodo Barrenador ( $R$. similis).

\section{MATERIALES Y MÉTODOS}

La extracción de los extractos cetónicos de higuerilla se realizó en el laboratorio de Procesos Agroindustriales de la Universidad de Caldas, y el efecto de estos extractos sobre el nematodo Barrenador $R$. similis se realizó en el laboratorio de Fitopatología de la Facultad de Ciencias Agropecuarias de la Universidad de Caldas.

Los materiales vegetales utilizados. Para el experimento fueron tejidos de raíces, tallos, hojas y frutos de plantas de higuerilla variedad Colbio RC09, los cuales fueron recolectados y empacados en bolsas de plástico; obtenidos en la granja Montelindo de la Universidad de Caldas, ubicada en la región de Santagueda, municipio de Palestina, departamento de Caldas, a una altitud de 1.010 msnm, con precipitación anual de $2100 \mathrm{~mm}$, temperatura promedio de $23^{\circ} \mathrm{C}$ y humedad relativa promedio de $76 \%$.

Los nematodos utilizados en el experimento. Se extrajeron de raíces de plátano Dominico Hartón parasitadas por $R$. similis, provenientes de la granja Montelindo de la Universidad de Caldas. La extracción de éstos se realizó en el Laboratorio de Fitopatología del departamento de Producción Agropecuaria de la Facultad de Ciencias Agropecuarias de la misma Universidad, basados en el principio de flotación de los nematodos en azúcar según Meredith (1973) y Araya et al. (1995).

El procedimiento se realizó de la siguiente manera: las raíces se lavaron con agua, después de dejarlas secar a temperatura ambiente, se pesaron $40 \mathrm{~g}$ de ellas en una balanza Analytical Plus, marca Ohaus; con la ayuda de tijeras se cortaron transversalmente trozos de raíces de $1 \mathrm{~cm}$, que luego se homogenizaron. Estos trozos se colocaron dentro del vaso de una licuadora Osterizer $₫$, modelo $565-15$, con $300 \mathrm{~mL}$ de agua y luego se licuaron a alta velocidad por $30 \mathrm{seg}$. La solución del licuado fue depositada en un tamiz de $250 \mu \mathrm{m}$ el cual estaba colocado sobre un tamiz de $106 \mu \mathrm{m}$, y éste sobre otro de $25 \mu \mathrm{m}$. La muestra se lavó con agua a presión para que hubiera desprendimiento de los nematodos, y del material que quedaba en el tamiz de $25 \mu \mathrm{m}$, luego se depositó todo su contenido en tubos de centrifugación de $30 \mathrm{~mL}$ de capacidad. Posteriormente, se centrifugó a 3.800rpm durante $5 \mathrm{~min}$. 
Como consecuencia de la centrifugación hubo sedimentación de las partículas pesadas en el fondo del tubo y se procedió a eliminar el sobrenadante. Seguidamente, los tubos fueron llenados nuevamente con solución de sacarosa al $50 \%$ y sometidos a centrifugación a $3.800 \mathrm{rpm}$ durante $5 \mathrm{~min}$ con el propósito de que los nematodos quedaran flotando en la solución de sacarosa por densidad diferencial y fueran separados de las partículas más pesadas. Luego el sobrenadante se depositó en el tamiz de $25 \mu \mathrm{m}$ para lavar la sacarosa con agua corriente a presión baja y evitar que los nematodos fueran afectados por ésta. Finalmente se recogieron $20 \mathrm{~mL}$ de agua con nematodos en una caja de Petri.

Para la obtención de los extractos cetónicos de higuerilla. Acción de separar con un liquido, en este caso con acetona, una fracción específica de una muestra, se utilizó el método de Soxhlet descrito por Núñez (2008), en el cual inicialmente se recolectaban los tejidos de higuerilla, raíces, tallo, hojas y frutos, y se secaban en una estufa a $40^{\circ} \mathrm{C}$ durante $48 \mathrm{~h}$; después de ello, de cada tejido se obtuvieron los extractos cetónicos de la siguiente manera:

El material vegetal se sometió a un proceso de reducción de tamaño, aproximadamente $3 \mathrm{~mm}$, se pesaron $250 \mathrm{~g}$ de tejidos y se introdujeron en el extractor Soxhlet provisto de un cartucho de tela dentro de la cámara de extracción para evitar la obstrucción del equipo e interrupción del proceso de extracción. Después, con una probeta se midieron $500 \mathrm{~mL}$ de solvente, acetona, y se depositaron en el balón volumétrico, manejando siempre una relación sólido/líquido de $1 / 2$, proporción suficiente para mantener disolvente en el balón volumétrico durante el proceso de extracción. Posteriormente se instalaron los fluidos fríos o agua de condensación y luego los fluidos calientes, se utilizó como medio de calentamiento una estufa con el fin de evitar chispas o llama y poder controlar la temperatura por debajo de $35^{\circ} \mathrm{C}$, para evitar inactivar la ricina de los extractosa tal temperatura.

El proceso de extracción se mantuvo durante seis ciclos, con el fin de facilitar el proceso de percolación de los metabolítos secundarios de los tejidos de higuerilla. Los seis ciclos reportados se mantuvieron debido a que con un número mayor de ciclos no se encontró cambio en la intensidad del color por taninos y clorofilas de los extractos cetónicos para ninguno de los tejidos utilizados. El primer ciclo de extracción demoró aproximadamente $90 \mathrm{~min}$, y los cinco ciclos restantes, aproximadamente $30 \mathrm{~min} \mathrm{c} / \mathrm{u}$. Cada extracción Soxhlet de cada tejido de higuerilla se realizó en aproximadamente $4 \mathrm{~h}$.Terminado el proceso de extracción Soxhlet, se dejó enfriar el extracto cetónico de cada tejido 
de higuerilla. Para conservar las propiedades de los extractos, éstos se depositaron en botellas de color ámbar y se almacenaron en refrigeración y ausencia de luz a $4^{\circ} \mathrm{C}$.

Debido a que los extractos cetónicos de los cuatro tejidos de higuerilla obtenidos presentaron aproximadamente $0.9 \%$ de risinina y principios amargos, se llevaron a un proceso de rota-evaporación al vacío en un equipo Buchi, utilizando un rota-evaporador de marca Water Bath 480, para obtener extractos acuosos libres de acetona. El agua en los extractos fue la proveniente de la humedad de los tejidos; de tal manera se garantizaba que el efecto nematicida o nemostático de cada tejido a evaluar fuera ocasionado sólo por los extractos cetónicos de cada tejido.

El proceso se llevó a cabo a presión de vacío, aproximadamente 0.5 atmósferas, temperatura de $35^{\circ} \mathrm{C}$ y rotor a una velocidad media. Como indicativo del proceso de separación de la acetona se tuvo en cuenta la formación de neblina, dado que la acetona presenta condensación tipo película y el agua tipo gota. Con ello se impidió que la muestra se desecara; los tiempos de separación variaron, dado que la composición de los tejidos es diferente y en algunos se presenta formación de espumas.

Los extractos acuosos obtenidos del proceso de rotaevaporación se almacenaron a $4^{\circ} \mathrm{C}$, en ausencia de luz, a cada uno de ellos se les determinó el pH para descartar que se presentara un posible efecto nematicida por acidez. Los valores de $\mathrm{pH}$ fueron los siguientes: 5,$72 ; 5,65 ; 5,84$; y 7,34 para hojas, tallos, raíces y frutos, respectivamente.

Para la obtención de las concentraciones de los extractos cetónicos de higuerilla ( $R$. communis) se tomaron los extractos cetónicos de raíces, tallos, hojas y frutos, los cuales se evaluaron en las concentraciones del 25; 50 y $100 \%$ sobre $R$. similis en condiciones in vitro. La concentración del $100 \%$ fue la misma solución madre de cada tejido, a partir de ella se obtuvieron diluciones al $50 \%$ y $25 \%$ con agua destilada y se almacenaron en las condiciones antes indicadas hasta su aplicación.

Para la estandarización de la dosis de Carbofuran aplicada sobre los nematodos, se tuvieron en cuenta ensayos previos al establecimiento de esta investigación, se aplicó la dosis de Carbofuran recomendada en la etiqueta del producto químico, la cual era de $240 \mathrm{ppm}$, aunque tal dosis tenía un efecto nematicida inferior al $50 \%$ sobre $R$. similis $48 \mathrm{~h}$ después de ser aplicado, tiempo en el cual los extractos acuosos de los tejidos de higuerilla mostraron un efecto nematicida, por lo que se aumentó la dosis de 
Carbofuran a 330ppm (datos no mostrados) donde se tuvo una mortalidad del 98\%, para poder hacer una comparación de su efecto nematicida a las $48 \mathrm{~h}$ acorde con el efecto nematicida de los extractos acuosos de higuerilla.

Para la evaluación de los extractos cetónicos de tejidos de higuerilla sobre $R$. similis, se tomaron tres cajas de Petri de $5 \mathrm{~cm}$ de diámetro $X 1 \mathrm{~cm}$ de alto, en las cuales se colocaron con una micropipeta de a $20 \mu \mathrm{L}$ de agua con 50 hembras de $R$. similis; luego en cada una de ellas, se depositaron $2 \mathrm{~mL}$ del extracto cetónico de raíces de higuerilla en las concentraciones del 25; 50 y $100 \%$. El mismo procedimiento se realizó con los extractos cetónicos de tallos, hojas y frutos; al igual que con el testigo químico Carbofuran en la dosis evaluada de 330 ppm y con el testigo absoluto agua. Por cada tejido y concentración se tuvieron tres repeticiones con sus respectivos testigos químico y absoluto.

Debido a la dificultad de separar los 50 nematodos para todas las cajas de Petri de todos los tratamientos, al igual que la dificultad para realizar las lecturas de las variables, se efectuó la evaluación individual de cada tejido de higuerilla. Con base en ello, en cada montaje se tenían cinco tratamientos que consistían en las tres concentraciones de cada tejido, 25; 50 y $100 \%$, y el testigo absoluto y el químico, cada uno con tres repeticiones, para un total de 15 cajas de Petri, las cuales fueron colocadas en la mesa del laboratorio en un diseño experimental completamente al azar. Para aumentar la confiabilidad de los resultados obtenidos, dicho procedimiento se repitió tres veces en diferentes tiempos.

Después de $48 \mathrm{~h}$ de estar expuestos los nematodos a diferentes tratamientos, en cada caja de Petri se evaluó el número de hembras adultas de $R$. similis muertas. Luego de evaluar esta variable, los nematodos se colocaron en agua durante $4 \mathrm{~h}$, en seguida se evaluó el número de hembras vivas después de ser expuestas a la acción del agua destilada. La diferencia entre el porcentaje de hembras inactivas obtenidas en la primera lectura a las $48 \mathrm{~h}$ y el porcentaje de hembras muertas en la segunda lectura a las $4 \mathrm{~h}$ permitió calcular el efecto nemostático, el cual se refiere a la suspensión de la actividad de un nematodo cuando las condiciones ambientales son desfavorables.

Para evaluar el efecto nemostático, las hembras de $R$. similis se pasaron a un tamiz de $25 \mu \mathrm{m}$, se les lavó el extracto con agua destilada usando un frasco lavador y se volvieron a pasar con agua destilada a las cajas de Petri debidamente marcadas. Las hembras adultas se observaron bajo un estéreo-microscopio marca LW 
Scientific, se cuantificaron y clasificaron en móviles e inmóviles; las últimas se diferenciaron por su aspecto rectilíneo y por no responder al ser estimuladas con una aguja.

Para determinar si las hembras fueron destruidas por la acción de alguno de los extractos cetónicos de los tejidos de higuerilla, en cualquiera de sus concentraciones o por el testigo químico o el agua, se determinó la diferencia entre el número de hembras móviles presentes por unidad experimental conformada porcada caja de Petri, antes y después de ser expuestas a la acción de los tratamientos por $48 \mathrm{~h}$ y después de estar por $4 \mathrm{~h}$ en el agua destilada.

Se realizó la prueba de Bradford (Bradford, 1976), la cual permite cuantificar las proteínas presentes en los extractos cetónicos para garantizar que el efecto nematicida de los extractos no fue debido a la acción de trazas de acetona que podían haber quedado después de la rota-evaporación.

Para el análisis de los datos. En cada extracto acuoso de higuerilla se estimó el promedio y variación con la variable mortalidad de hembras de $R$. similis, bajo un diseño completamente al azar. Cuando el análisis de varianza mostró diferencia de tratamientos en las variables evaluadas, se aplicó la prueba de comparación de medias de Tukey al $5 \%$.

\section{RESULTADOS Y DISCUSIÓN}

Después de realizar la prueba de Bradford. Se encontraron diferentes cantidades de albúminas, globulinas, prolaminas y glutelinas en los extractos cetónicos de hojas, raíces, tallos y frutos de higuerilla (Tabla 1). El valor más alto de albúminas se encontró en los extractos cetónicos de frutos con 0,366 nm, superando en 0,032 nm al patrón de comparación que fue la pasta de fríjol (Tabla 1).

Tabla1: Cantidad de proteinas $(\mathrm{nm})$ presentes en los extractos cetónicos de tejidos de higuerilla ( $R$. communis)

\begin{tabular}{lccccc}
\hline Proteinas & $\begin{array}{c}\text { Frijol } \\
(\mathrm{nm})\end{array}$ & $\begin{array}{c}\text { Raices } \\
(\mathrm{nm})\end{array}$ & $\begin{array}{c}\text { Tallos } \\
(\mathrm{nm})\end{array}$ & $\begin{array}{c}\text { Hojas } \\
(\mathrm{nm})\end{array}$ & $\begin{array}{c}\text { Frutos } \\
(\mathrm{nm})\end{array}$ \\
\hline Albúminas & 0.098 & 0.265 & 0.018 & 0.032 & 0.366 \\
\hline Globulinas & 0.025 & 0.061 & 0.032 & 0.158 & 0.094 \\
\hline Prolaminas & 0.152 & 0.577 & 0.036 & 0.160 & 0.685 \\
\hline Glutelinas & 0.166 & 0.396 & 0.066 & 0.016 & 0.083 \\
\hline
\end{tabular}


La ricina es una albúmina que está presente en las semillas de los frutos de higuerilla (Moshkin, 1986). Por ello, se encontró un contenido mayor de albúminas, ricina, en las semillas de higuerilla, y por ende en los extractos cetónicos, lo cual pudo ocasionar el efecto nematicida mayor sobre $R$. similis como se explicará más adelante. Dichos resultados también confirman la mayor concentración de metabolitos secundarios extraídos por el método de Soxhlet, permitiendo evaluar de una manera precisa el efecto nematicida sobre los fitonematodos. Asimismo, no se puede descartar también un efecto nematicida de la ricinina que es un alcaloide presente en los tejidos de higuerilla (Leite et al. 2005).

El extracto cetónico de raíces fue el segundo en contenido de albúminas con un valor alto de 0,265 nm, en comparación con la pasta de fríjol (Tabla 1). A pesar de que se han realizado estudios diversos y satisfactorios con extractos acuosos de raíces de higuerilla sobre poblaciones de nematodos, se puede suponer que no sólo es efecto de la ricina, ya que varios autores (Pinkerton et al. 1999; Leite et al. 2005) argumentan que esta albúmina sólo se encuentra en los frutos, por lo que sería muy importante determinar la presencia o no de ricina en raíces de higuerilla, para conocer si el efecto nematicida del extracto de raíces encontrado en este estudio fue debido a la ricina u otro compuesto.

Efecto de extractos cetónicos de higuerilla ( $R$. communis) sobre el nematodo Barrenador (R. similis). El análisis de varianza y la prueba de comparación múltiple de Tukey al 5\%, permitieron determinar que se presentaron diferencias estadísticas entre los extractos cetónicos de los tejidos de higuerilla y los testigos en el efecto nematicida sobre el nematodo Barrenador $R$. similis. En los tres tiempos de lectura, los tratamientos de los extractos cetónicos de frutos, raíces y hojas de higuerilla en la concentración de $100 \%$, tuvieron un efecto nematicida entre 73 y $89 \%$, sin diferencias estadísticamente significativas con el testigo químico que tuvo valores entre 82 y 98\%; estos tratamientos mostraron diferencias significativas al testigo agua que presentó valores menores entre 0,7 y $12 \%$ (Figuras 1 y 2 ). Los anteriores tratamientos presentaron diferencias significativas a los tratamientos del extracto cetónico en las concentraciones de 25 y $50 \%$ que presentaron una mortalidad de $R$. similis menor entre 20 y $67 \%$ (Figura 1). 

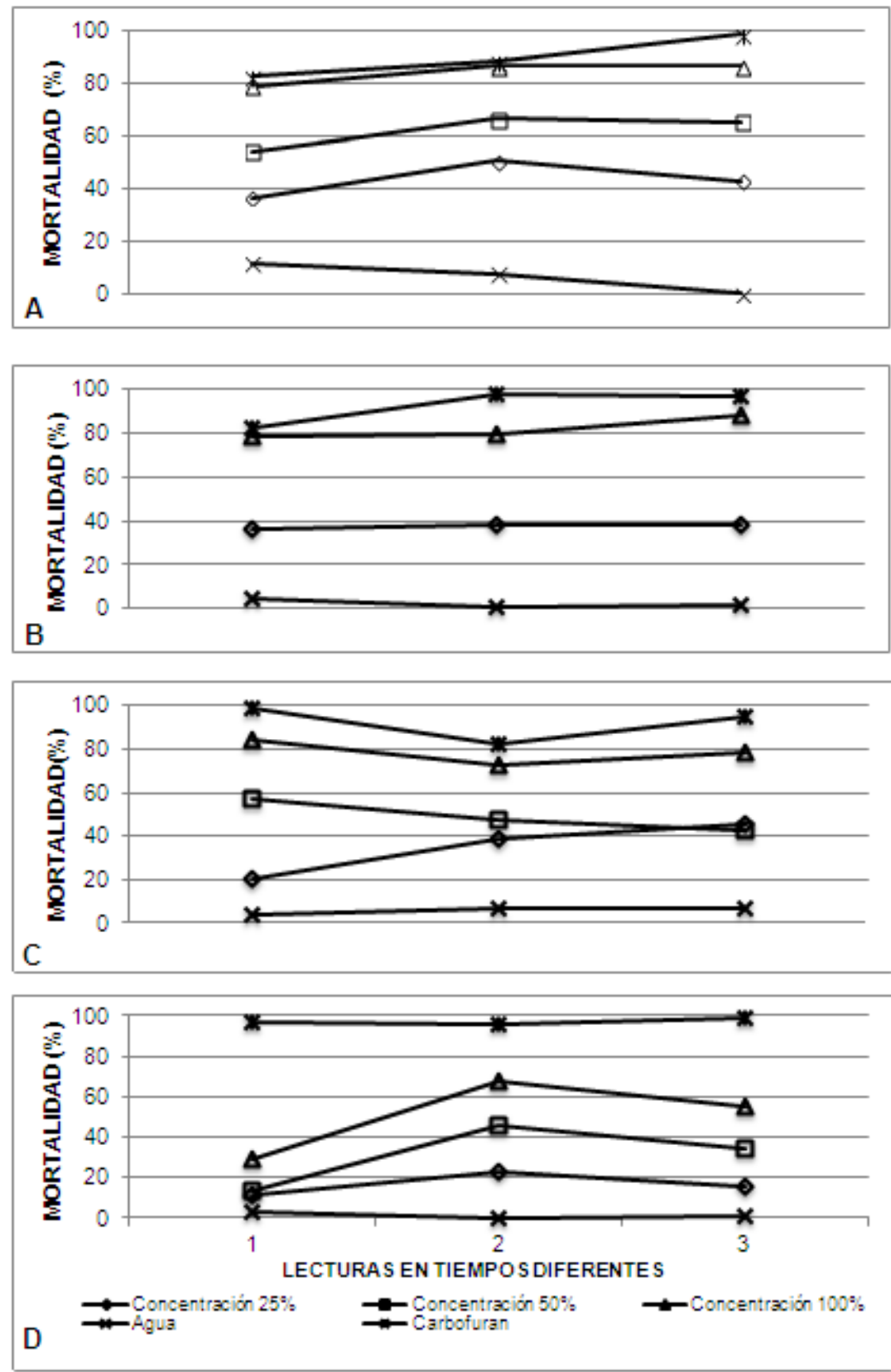

Figura 1. Efecto nematicida (\%) de extractos cetónicos de frutos (A), raíces (B), hojas (C) y tallos (D) de higuerilla sobre $R$. similis, en condiciones in vitro, en tres tiempos de lectura diferentes. 

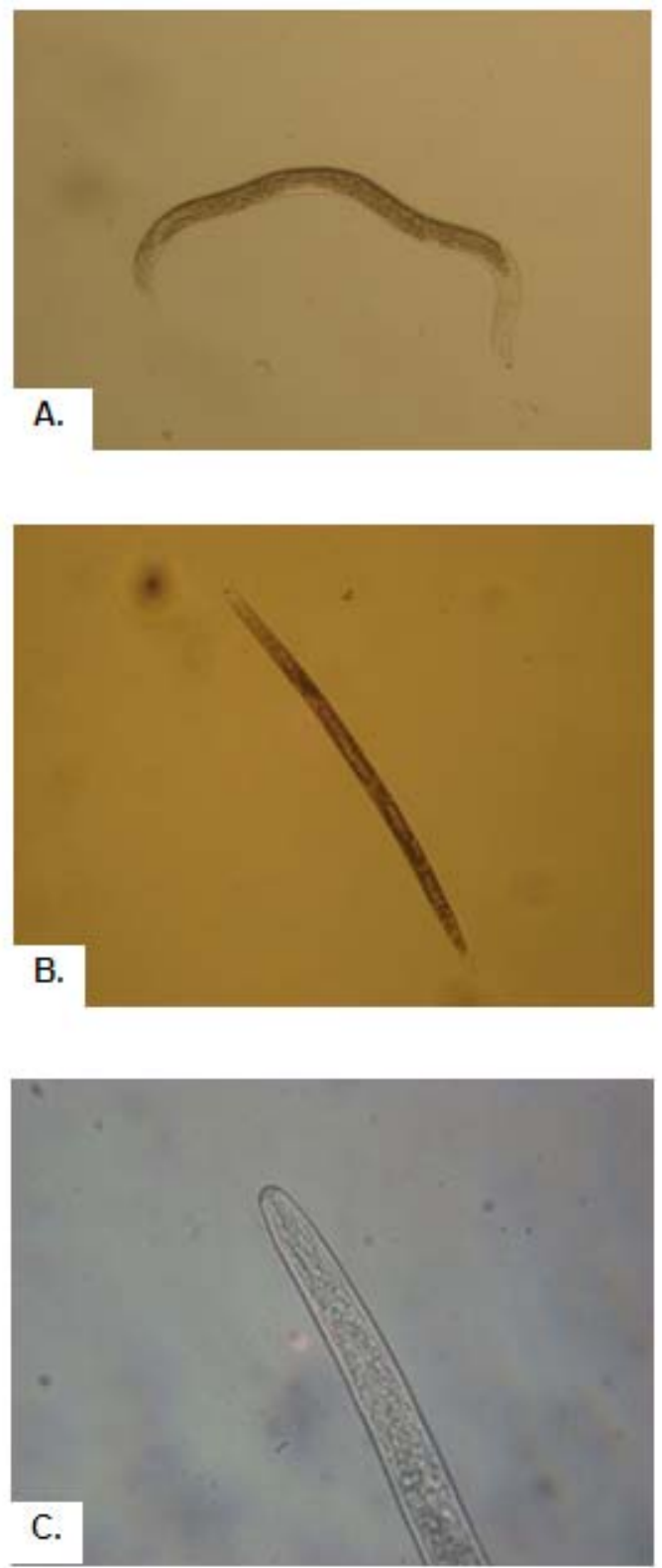

Figura 2. A. Adulto de R. similis vivo después de ser expuesto a la acción del testigo agua. B y

C. Adulto completo y región anterior de hembra de $R$. similis muertos, respectivamente, después de $48 \mathrm{~h}$ de ser expuesto al extracto cetónico de frutos de higuerilla.

El efecto nematicida mayor a $79 \%$ del extracto cetónico de frutos (Figura 1), probablemente se debió a que la obtención de los extractos por la metodología de Soxhlet permitió obtener de los frutos de higuerilla una cantidad mayor de metabolitos secundarios como la ricina, proteína que según Gardner et al. (1960), se encuentra exclusivamente en el endosperma de las semillas de higuerilla, además de ser una proteína altamente tóxica para animales (Barbieri et al. 1993; Van Damme et al. 2001). 
Igualmente, los resultados del efecto nematicida del extracto cetónico de frutos se confirman con los datos obtenidos en la prueba de Bradford, ya que dichos extractos mostraron mayor presencia de albúminas como la ricina, registrando el mayor valor con $0.368 \mathrm{~nm}$ en la lectura de la absorbancia a $540 \mathrm{~nm}$

Los resultados de esta investigación permitieron demostrar que el extracto cetónico de frutos en la concentración del $100 \%$ tiene efecto nematicida sobre $R$. similis en condiciones in vitro. A pesar de que este extracto tuvo una diferencia en la mortalidad con el testigo químico, la cual no superó el 11\% (Figura 1), hay que destacar que el Carbofuran no fue utilizado en la dosis comercial de 240 p.p.m., para el control de dicho fitonematodo, sino una dosis mayor de 330 p.p.m., lo cual demuestra que los tratamientos con los extractos acuosos tuvieron un excelente efecto sobre la mortalidad de $R$. similis a las $48 \mathrm{~h}$ de evaluación.

Asimismo, los compuestos tóxicos como la ricina y la ricinus-aglutinina, obtenidos de los frutos de higuerilla tienen la capacidad para unirse fuertemente a los anfidios de los nematodos fitoparásitos formadores de nudos (Meloidogyne incognita, M. javanica), Naccobus aberrans y Lesionador (Pratylenchus coffeae), lo cual modifica su comportamiento quimiotáctico (Rich et al. 1989; Ritzinger \& Mcsorley, 1998), estos compuestos probablemente tuvieron un efecto similar sobre las hembras de $R$. similis.

Otro componente que pudo influir en el efecto nematicida de los extractos cetónicos de los frutos, raíces y hojas de higuerilla fue el alcaloide ricinina, que al actuar en conjunto con la ricina, pudo haber potencializado su efecto neamaticida. Leite et al. (2005), encontró este alcaloide en todas las partes de la planta de higuerilla, el cual es uno de los principales componentes tóxicos de la torta de higuerilla, posee la formula molecular $\mathrm{C}_{8} \mathrm{H}_{8} \mathrm{~N}_{2} \mathrm{O}_{2}$, con el nombre químico de 3 ciano-4 metoxim-N-metil-2-piridona. De acuerdo con Moshkin (1986), el contenido de ricinina varía entre los tejidos de higuerilla con valores de $1,3 \%$ en materia seca de hojas, $2.5 \%$ en plantas estioladas, $0,03 \%$ en el endospermo de las semillas y $0,15 \%$ en la cáscara de la semilla.

Tales resultados coinciden con los obtenidos por Rich et al. (1989) quienes evaluaron el efecto de la ricina sobre la movilidad del nematodo formador de nudos Meloidogyne incognita, ellos aplicaron ricina en concentraciones de 2.5; $5 ; 10 ; 20$ y $40 \mu \mathrm{g} \mathrm{mL}^{-1}$ y encontraron que al aumentar la concentración de la ricina se disminuía la movilidad de los estados juveniles, j2, de este nematodo. Por ejemplo, en la 
concentración de ricina de $10 \mu \mathrm{g} \mathrm{mL}^{-1}$ se obtuvo una reducción de la movilidad de los j2 del 25\%, en comparación con la concentración de $20 \mu \mathrm{g} \mathrm{mL}^{-1}$ que tuvo una reducción del $45 \%$ de movilidad. Otro estudio que confirma la relación directa del aumento de la concentración de los extractos cetónicos de hojas de higuerilla con el aumento del efecto insecticida de las mismas fue realizado por Collavino et al. (2006), sobre larvas de la polilla de las harinas Plodia interpunctella Hübner, ellos aplicaron los extractos en tres concentraciones de $5 ; 10$ y $15 \%$ y obtuvieron finalmente que la mayor concentración, $15 \%$, fue la que presentó una mortalidad del $100 \%$ a los 11 días, mientras que las concentraciones de 10 y $5 \%$ tuvieron efecto a los 30 y 40 días, respectivamente, y matando sólo el $50 \%$ de las polillas.

Asimismo, estos resultados son acordes con los obtenidos por Ramírez et al. (2001), debido a que los metabolitos secundarios de las plantas, extraídos con solventes orgánicos permiten obtener una cantidad mayor que los obtenidos con extractos acuosos. También Rozo et al. (2008) Ilegaron a la conclusión que se logra un mayor efecto biocida sobre larvas de Aedes aegypty Linnaeus al aplicar extractos cetónicos de Eupatorium mycropyllum L. $\mathrm{F}$., concentraciones de $10 \mathrm{mg} \mathrm{L}^{-1}, 20 \mathrm{mg} \mathrm{L}^{-1}, 30 \mathrm{mg} \mathrm{L}^{-1}, 40 \mathrm{mg}$ $\mathrm{L}^{-1}, 50 \mathrm{mg} \mathrm{L}^{-1}$, al obtenerse una mortalidad de 6, 23, $39 \mathrm{y}$ $96 \%$, respectivamente, en comparación con los extractos acuosos, $500 \mathrm{mg} \mathrm{L}^{-1}, 1500 \mathrm{mg} \mathrm{L}^{-1}$ y $2500 \mathrm{mg} \mathrm{L}^{-1}$, que tuvieron valores menores de mortalidad con 9,12 y $20 \%$, para cada uno.

Adegbite \& Adesiyan (2005), cuando evaluaron el efecto del extracto acuoso de raíces de higuerilla sobre la mortalidad de estados juveniles, j2, de Meloidogyne incognita, observaron que después de $24 \mathrm{~h}$ de ser expuestos 20 nematodos a los extractos con $10 \mathrm{~mL}$ por caja de Petri, y en concentraciones de $0 ; 5 ; 10 ; 20$ y $100 \%$, encontraron una mortalidad de 1,$7 ; 9,0 ; 23,6 ; 27,9$ y $68,3 \%$, respectivamente, lo cual demostró que las raíces de higuerilla también poseen propiedades nematicidas, que en la medida que se aumentó la concentración en la dosis fue mayor el efecto nematicida como ocurrió en esta investigación con los extractos cetónicos de raíces, hojas y frutos.

De los cuatro extractos cetónicos de higuerilla evaluados tales como raíces, tallos, hojas y frutos, el efecto nematicida menor fue el obtenido con el extracto cetónico de tallos, el cual en los tres tiempos de lectura y en la concentración del $100 \%$ tuvo un promedio del $51 \%$; mientras en las demás concentraciones el efecto fue 
inferior al $45 \%$. Tales valores fueron estadísticamente diferentes al testigo agua y Carbofuran que presentaron el efecto nematicida menor y mayor con valores entre 0,5 y 3,3\%; 96 y $99 \%$, respectivamente (Figura 1).

Los anteriores resultados coinciden con la cantidad menor de metabolitos secundarios encontrados en los extractos cetónicos de tallos realizada con la prueba de Bradford, cuyo valor fue de $0,018 \mathrm{~nm}$, siendo inferior en el contenido de albúminas comparado con los demás extractos cetónicos evaluados y contrastando con 0,366 nm de albúminas encontradas en los extractos cetónicos de frutos de higuerilla (Tabla 1).

Al analizar los resultados del efecto nematicida de los cuatro extractos cetónicos de higuerilla en una misma figura, se pueden apreciar fácilmente las diferencias entre los tratamientos. Se observa cómo los extractos cetónicos de frutos, raíces y hojas en la concentración del 100\% tuvieron el efecto nematicida mayor al $73 \%$, siendo estadísticamente igual al testigo químico que los superó en menos del 15\% (Figura 3).

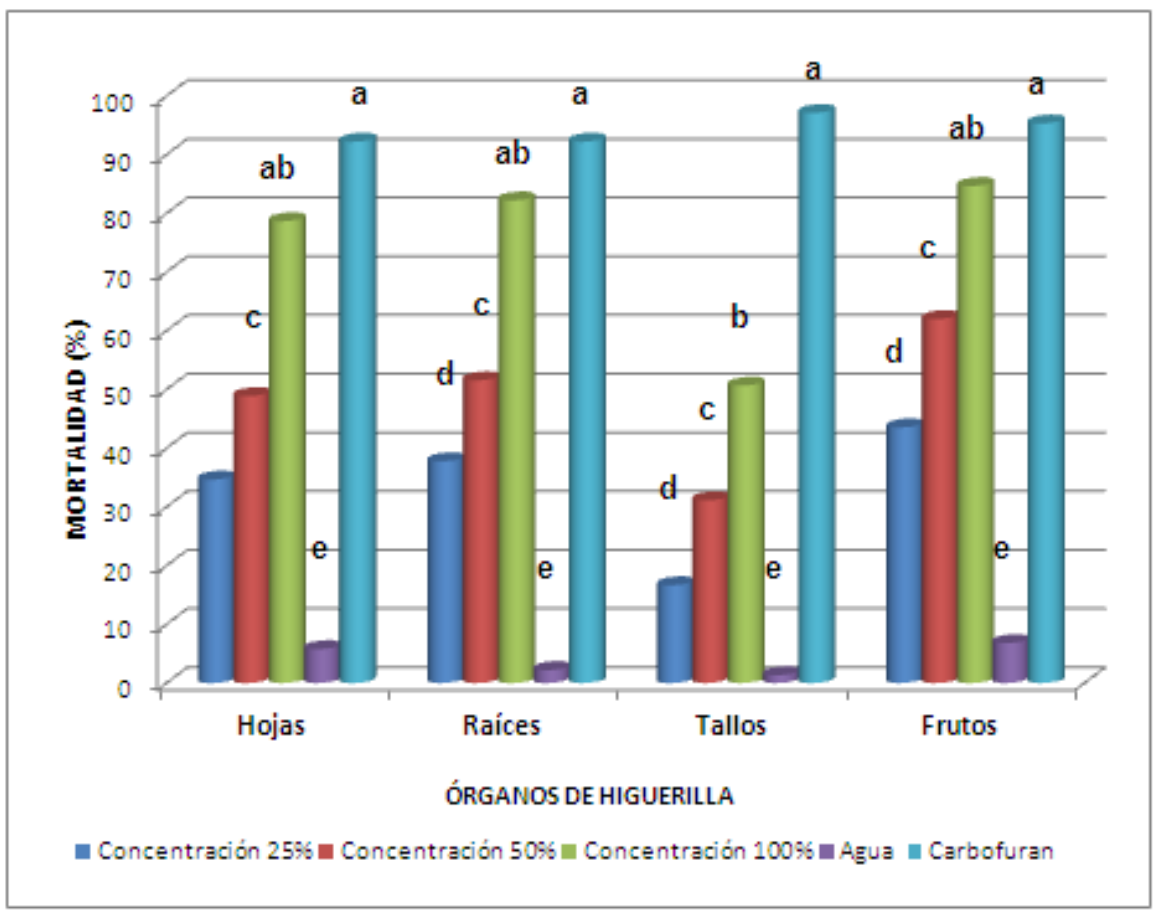

Figura 3. Efecto nematicida de extractos cetónicos de raíces, tallos, hojas y frutos de higuerilla sobre $R$. similis.

*Dentro de cada tejido de higuerilla, las columnas seguidas por la misma letra no se diferencian significativamente de acuerdo a la prueba de comparación múltiple de Tukey al $5 \%$.

Lo anterior indica que estos extractos cetónicos son promisorios para el manejo de $R$. similis en condiciones de campo. Asimismo, es de destacar que pese a que el 
testigo químico tuvo una mortalidad mayor de los nematodos, éste fue utilizado en una dosis mayor a la comercial como se explicó anteriormente, lo que permite concluir que dichos extractos controlaron de manera eficiente este fitonematodo en condiciones in vitro.

En todos los tejidos de higuerilla, cuando se aplicaron las concentraciones del 25 y $50 \%$, el efecto nematicida fue menor al encontrado en la concentración del 100\% de todos los tejidos de higuerilla con valores de 44 y $62 \%$ para frutos, 38 y $52 \%$ para raíces, 35 y 49 para hojas y 17 y $32 \%$ para tallos, respectivamente (Figura 3). Igualmente, los resultados mostraron que se presentó una relación directamente proporcional entre el aumento de la concentración del extracto cetónico de frutos y el efecto nematicida sobre $R$. similis, presentándose los mayores valores de mortalidad en la concentración del $100 \%$, y los menores en la concentración del 25\% (Figura 3).

Debido al efecto fitotóxico o nematicida de los extractos acuosos de los tejidos de higuerilla sobre $R$. similis, el cual se reflejó en la consistencia de los resultados en los tres tiempos de evaluación y en las tres concentraciones, 25, 50 y $100 \%$, no se encontró efecto nemostático, por lo que no se presentan datos.

\section{CONCLUSIONES}

La prueba de Bradford permitió conocer la presencia de proteínas en los extractos cetónicos de los tejidos de higuerilla, confirmando que el extracto cetónico de frutos tuvo una cantidad alta de albúmina, ricina u otro compuesto, que influyó en la mortalidad mayor de $R$. similis.

Los extractos cetónicos de frutos, raíces y hojas de higuerilla en la concentración del $100 \%$ y en tres tiempos diferentes de evaluación, tuvieron efecto nematicida sobre el nematodo Barrenador $R$. similis en condiciones in vitro comportándose igual al testigo Carbofuran después de 48 horas de ser aplicados.

\section{AGRADECIMIENTOS}

Los autores del artículo expresan los más sinceros agradecimientos al Dr. José Fernando Restrepo Henao por su gestión económica y por compartir conocimientos en el 
cultivo de Higuerilla. En esta investigación, la consecución de los materiales de higuerilla y su financiación fue realizada dentro del convenio de la Gobernación de Caldas y la Universidad de Caldas.

\section{BIBLIOGRAFÍA}

- Acacio-Bigi, M. J. A.; Hebling, O. C.; Bueno, F. C. \& Pagnocca, M. (1998). Toxicidade de extratos foliares de Ricinuscommunis L. Para operarias de Atta sexdensrubropilosa Forel. Rev. Bras. Ent (Brazil). 41(2-4): 239-243.

- Adegbite, A. A. \& S.O. Adesiyan. (2005). Root extracts of Plants to control Root-knot nematode on edible soya bean. World J. Agric. Sci., 1: 18-21.

- Araya, M. (2003). Situación actual del manejo de nematodos en banano (Musa $A A A$ ) y plátano (Musa $A A B$ ) en el trópico americano. En: Manejo Convencional y alternativo de la Sigatoka Negra, Nematodos y Otras Plagas Asociadas al Cultivo de Musáceas en los Trópicos. Rivas G. y Rosales, F. (eds.) INIBAP (Francia). pp. 79-102.

- Araya, M.; Centeno, M. \& Carrillo, W. (1995). Densidad poblacional y frecuencia de los nematodos parásitos de banano (Musa $A A A)$ en nueve cantones de Costa Rica. CORBANA (Costa Rica). 20(43): 6-11.

- Araya, M. \& De Waele, D. (2004). Spatial distribution of nematodes in three banana (Musa $A A A$ ) root parts considering two root thickness in three farm management systems. Acta Oecologica 26:137-148.

- Barbieri, L.; Battelli, M. G. \& Stirpe, F. (1993). Ribosomeinactivating proteins from plants. Biochim Biophys Acta 1154: 237-282.

- Blake, C. D. (1966). The histological changes in banana roots caused by Radopholussimilis and Helicotylenchusmulticinctus. Nematologica 12:129-137.

- Blake, C. D. (1961). Root rot of bananas caused by Radopholussimilis (Cobb) and its control in New South Wales. Nematologica 6: 295-310.

- Bradford, M. M. (1976). A rapid sensitive method for the quantitation of microgram quantities of protein utilizing the principle of protein dye-binding. Anal Biochem 72: 248-254.

- Brooks, F. E. (2008). Burrowing Nematode. The Plant Health Instructor. APS net (USA). Obtenido el: 4 de Marzo de 2011. Desde :http://www.apsnet.org/edcenter/intropp/lessons/Nematodes/Pages/Bu rrowingnematode.aspx

- CORPORACIÓN COLOMBIANA DE INVESTIGACIÓN AGROPECUARIA, CORPOICA. Centro de investigaciones La Selva. (2008). Higuerilla: Alternativa productiva, 
energética y agroindustrial para Colombia. 1 ed. Rionegro, Antioquia. Centro de Investigaciones La Selva-Corpoica. p. 38

- Céspedes, C. L.; Alarcón, J.; Aranda, E.; Becerra, J. \& Silva, M. (2001). Insect growth regulator and insecticidal activity of beta-dihydroagarofurans from Maytenuss pp. (Celastraceae) (abstract). Zeitschrift für Naturforschung-C. Journal of Biosciences 56: 603-613.

- Collavino, M.; Pelicano, A., \& Gimenez, R.A. (2006). Insecticide action of Ricinus communis L. on Plodia interpunctella Hbn. (Lepidoptera: Phycitinae). Revista de la Facultad de Ciencias Agrarias Universidad Nacional de Cuyo 38, pp. 13-18.

- FAOSTAT (2006). FAO On Line Statistical Database. Obtenido el: 4 de Marzo de 2011. Desde: www.faostat.fao.org.

- Fogain R. \& Gowen,S. R.(1997). Damage to roots of Musa cultivars by Radopholussimilis with and without protection of nematicides. Nematropica 27(1): 27-32.

- Fogain, R. (2000). Effect of Radopholussimilis on plant growth and yield of plantain (Musa $A A B$ ). Nematology. 2, pp. 129-133.

- Gowen, S.; Quénéherve, P. \& Fogain, R. (2005). Chapter 16: Nematodes parasites of bananas and plantains. pp. 611643. En: Plant Parasitic Nematodes in Subtropical and Tropical Agriculture. Edited by: Luc, M.; Sikora, J. \& Bridge, J. Cabi Bioscience, Egham (United Kingdom).

- González A, A.; Del Pozo N, E.; Galván P, B.; González C, A. \& González C, J. (2006). Extractos vegetales y aceites minerales como alternativa de control de mosca blanca (Bemisia spp.) en berenjena (Solanum melongena L.) en el Valle de Culiacán, Sinaloa, México. Revista UDO Agrícola 6 (1): pp. 84-91.

- Holfelder, M. G. A.; Steck, M.; Komor. E. \& Seifert, K. (1998). Ricinine in phloem sap of Ricinuscommunis. Phytochemistry. 47 (8): pp.1461-1463.

- Kouri, J.; Ferreira Dos Santos, R. \& Lemos, B. M. A. (2006). Cultivo da mamona-importancia económica. En: Embrapa Algodao-sistemas de producao (versao electrónica). 4-2a Edicao. Obtenido el 15 de Marzo de 2011. Desde: http: // sistemas de producao.cptia.embrapa.br/Fontes HTML/mamoma/cultivodamamona-2ed/importancia.htmlg.

- Leite, A. C.; Bueno, F. C.; Oliviera, C. G.; Fernandes, J. B.; Viera, P. C.; Da Silva, M. F. G. F.; Bueno, O. C., Pagnocca, F. C.; Hebling, M. J. A., \& BACCI, M. Jr. (2005). Limonoids from Cipadessafruticosa and Cedrelafissilis and their insecticidal activity. J. Braz. Chem. Soc., 16 (6B): 13911395.

- Loos, C. A. \& Loos, S. (1960). The blackhead disease of bananas (Musa acuminata). Proc. Helminthol. Soc. Wash. 27: 189-193. 
- Marín, D.; Sutton,T.B. \& Barker, K.R. (1998). Dissemination of bananas in Latin America and the Caribbean and its relationship to the occurrence of Radopholus similis. Plant Disease (USA). 82 (9). pp: 964-974.

- Mazzani, E. (2007). El tártago: la planta, su importancia y usos. En Revista Digital del Centro Nacional de Investigaciones Agropecuarias. CENIAP HOY. Abril a Diciembre, 2007.No. 14, pp. 1-9.

- Marbán, N.; Jeyaprakash, A.; Jansson, H. B.; Damon J. R. R. A. \& Zuckerman, B. M. (1987). Control of root-knot nematodes on tomato by lectins. Journal of Nematology 19: 331-335.

- Meredith, J. (1973). Algunos métodos de campo y laboratorio para trabajar con nematodos. Maracaibo (Venezuela). P. pp. 44.

- Moens, T.; Araya, M.; Swennen, R. \& De Waele, D. (2004). Enhanced biodegradation of nematicides after repetitive applications and its effect on root and yield parameters in commercial banana plantations. Bio Fertil Soils 39: 407-414.

- Montiel, C.; Sosa, L.; Medrano, C. \& Romero, D. (1997). Nematodos fitoparásitos en plantaciones de plátano (Musa $A A B)$ de la margen izquierda del río Chana. Estado Zulia (Venezuela). Departamento Fitosanitario. Facultad de Agronomía. Universidad de Zulia. Venezuela. pp: 245-251.

- Moshkin, V. A. (1986). Economic importance and regions of cultivation of castor. In: Moshkin, V. A. (Ed.). Castor. Moscow. Kolos. pp. 1-5.

- Núñez, C. E. (2008). Extracciones con Equipo SOXHLET. Obtenido el 15 de Marzo de 2011. Desde: http://www.cenunez.com.ar/Documentos\%20lab.\%20quím/ Extracción\%20con\%20equipo\%20Soxhlet.pdf.

- Oramas, D. \& Román, J. (2006). Histopatología de los nematodos Radopholus similis, Pratylenchus coffeae, Rotylenchulus reniformis y Meloidogyne incognita en plátano (Musa acumulata X M. balbisiana, AAB). J. Agric. Univ. P.R. 90 (1-2): 83-97.

- Pinkerton, S. D.; Rolfe, R.; Auld, D.L. (1999). Selection of Castor with divergent concentration of ricin and Ricinuscommunisagglutinin. Crop Science 39 (2): pp. 353357.

- Ramírez, L.A.; García, L. E.; Rodríguez, C. \& Castro, A. E. (2001). Evaluación del efecto insecticida de extractos de plantas sobre Leptophobia aripa elodia. Manejo Integrado de Plagas (Costa Rica) 60: 50-56.

- Rich, J. R.; Rahi, G. S.; Opperman, C. H. \& Davis, E. L. (1989). Influence of the castor bean (Ricinuscommunis) lectin (ricin) on motility of Meloidogyne incognita. Nematropica 19: 99-103.

- Rodríguez, C. (2005). Plantas contra plagas 2 Epazote, hierba de la cucaracha, paraíso, higuerilla y sabadilla. 1 (ed.) Tlaxcala (México). Rapal, Rapam, Somas. Instituto Tecnológico del Altiplano de Tlaxcala, p. 209 Rodríguez, H. 
C. \& Lagunes, A. (1992). Plantas con propiedades insecticidas. Resultados de pruebas preliminares en laboratorio, campo y granos almacenados. Agroproductividad 1:17-25.

- Sarah, J. L.; Pinochet, J. \& Stanton, J. (1996). Plagas de Musa. Hoja Divulgativa Número1. El Nematodo Barrenador del Banano Radopholussimlis Cobb. Inibap. Montpelier (Francia). Diciembre. 1996. pp. 1-2.

- Scarpa, A.; Guerci, A. (1982). Various uses of the castor oil plant (Ricinuscommunis.): A review. J. Ethnopharm. 5: 117137.

- Topping, M. D.; Henderson, R. T. S.; Luczynska, C. M. \& Woodmass, A. (1982). Castor bean allergy among workers in the felt industry. Allergy, 37: 603-608.

- Thorne, G. (1961). Principles of nematology. Mc Graw Hill (New York). p. 553

- Valette, C.; Andary, C.; Geiger, J. P.; Sarah, J. L. \& Nicole, M. (1998). Histochemical and cytochemical investigations of phenols in roots of banana infected by the burrowing nematode Radopholussimilis. Phytopathology 88: pp. 11411148.

- Van Damme, E. J. M.; Hao, Q.; Chen, Y.; Barre, A.; Vandenbussche, F. \& Desmyter, S. (2001). Ribosomeinactivating proteins: a family of plant proteins that do more than inactivate ribosomes. CRC Crit Rev Plant Sci 20: pp. 395-465.

- Verduzco, L.; Farias, J.; Orozco, M. \& Guzmán, S. (1996). Efecto de la incorporación de plantas y aplicación de nematicidas sobre el control de nematodos agalladores. Revista Mexicana de Fitopatología 14:168.

1. Ing. Agrónomo, Universidad de Caldas.

2. Profesor Auxiliar, Facultad de Ciencias Agropecuarias, Universidad de Caldas. Correo electrónico: oscar.guzman@ucaldas.edu.co

3. Profesor Asociado, Universidad de Caldas. Correo electrónico: luis.mejia_g@ucaldas.edu.co 